\title{
Miniaturization of cyclic voltammetry electronic systems for remote biosensing
}

\begin{abstract}
Although there are commercial tools available for electrochemistry in biosensing, these are normally expensive or their size is not suitable for portable applications. This article describes the design and fabrication of a low-cost 20 grams USB or Bluetooth controlled potentiostat that can apply potentials in the range of $\pm 1.65 \mathrm{~V}$, can measure from microamperes to maximum $10 \mathrm{~mA}$, and has the ability to send and receive data via USB or remotely via Bluetooth using a low power voltage supply (USB or LiPo battery) allowing its use in portable applications such as remote biosensors.
\end{abstract}

Keywords: potentiostat, electrochemistry, biosensors, electronic systems, redox reactions, cyclic voltammetry
Volume 3 Issue 3 - 2017

\author{
Crhistian C Segura, Johann F Osma \\ Department of Electrical and Electronics Engineering, \\ Universidad De Los Andes, Colombia
}

\begin{abstract}
Correspondence: Johann F Osma, CMUA, Department of Electrical and Electronics Engineering, Universidad de los Andes, Colombia, Email jf.osma43@uniandes.edu.co
\end{abstract}

Received: September 29, 2017 | Published: October 25, 2017

\section{Introduction}

The electrochemistry is the branch of chemistry that studies the interaction between the chemical reactions and the electric energy produced or consumed by them. Those measurements have been made using electrochemical cells which are made from three electrodes and a potentiostat. ${ }^{1}$ This system generates a controlled voltage that excites the cell and measure the current generated by it. In the development of electrochemical measurement systems and distribution to the final customer, companies such as Gamry (USA), Palm Sense (Netherlands) and Metrohm (Netherlands) have designed tools for measuring electrochemical reactions. These electrochemical measurement tools are employed in industry and academia frequently. ${ }^{2-6}$ Nevertheless, the potentiostat marketed by any of the above-mentioned brands can cost more than $\$ 2,000$. One of the alternatives with a lower cost as the PGSTAT101 from AUTOLAB $®$ (Netherlands) involves the increase in the dimensions of the device, which could affect the designs on a minimum scale. Therefore, there are researchers developing low cost and custom made potentiostats ${ }^{7-9}$ and in some cases also including a graphic user interface (GUI) to display the data and change the settings. This GUI is usually developed to work on a PC through a USB connection, ${ }^{11-13}$ while other approaches are targeting the communication to mobile phones and their operational systems (e.g. Android OS). ${ }^{10}$

However, in order to reduce the size and complexity of the custommade potentiostat only some features can be implemented, being the most used measurement the cyclic voltammetry $(\mathrm{CV})$. The use of $\mathrm{CV}$ as a measuring technique has been highly explored, and so, the most common small, integrated or low-cost approximations of these equipment are based on the CV feature. ${ }^{9,11,14-16}$ Additionally, the CV is a very useful technique in the identification of oxidation-reduction (Redox) processes, an can be a meaningful tool for the measuring of portable biosensors. . $^{10,11,13,14,16-20}$ The present work proposes the design and assembling of a low cost potentiostat as an alternative to develop a low cost miniaturized system for remote biosensing, which is able to run cyclic voltammetry measurements. The performance of the developed circuit was validated using gold electrodes and a solution of $0.5 \mathrm{mM}$ potassium ferricyanide/ferrocyanides. Results were compared to commercial potentiostat PGSTAT101 from AUTOLAB (Netherlands) to validate its functionality.

\section{Materials and methods}

\section{Materials}

Potassium hexacyanoferrate(II) trihydrate and potassium ferricyanide(III) $\left(\mathrm{K}_{3}\left[\mathrm{Fe}(\mathrm{CN})_{6}\right]\right)$ were bought from SIGMA ALDRICH, (USA) both are reactive grade. The MSP430G2553 microcontroller, LMC7660 switched capacitor voltage converter and LM358 low power dual-operational amplifiers, was bought from Texas Instruments, (USA). For the validation measurements a Potentiostat galvanostat, PGSTAT101 from AUTOLAB (Netherlands) and the same electrodes are used in addition to the software NOVA 2.0 form Metrohm company (Netherlands).

\section{Preparation of solutions}

The test solution was prepared using $100 \mathrm{~mL}$ of potassium ferricyanide and potassium hexacyanoferrate at a concentration on $5 \mathrm{mM}$ each one, for testing the CV $10 \mu 1$ of the solution was placed on top of the working electrode (WE) for measurement.

\section{Electronic and software}

The electrochemical cells used for the measurement tests contained three electrodes per cell, the reference electrode (RE), the working electrode (WE) and the counter electrode (CE) (Figure 1). These cells have three electrodes made of gold $(\mathrm{Au})$, with a distribution similar to the screen-printed electrodes from DropSens (Spain). ${ }^{13}$ The electrodes used in the test were fabricated in a clean room, evaporating a $100 \mathrm{~nm}$ $\mathrm{Au}$ layer on a $5 \mathrm{~nm}$ Chrome $(\mathrm{Cr})$ layer on microscope glass slides, the physical vapor deposition of $\mathrm{Au}$ and $\mathrm{Cr}$ was accomplished with a Edwards Auto 306 physical thermal evaporator (Moorfield, Knutsford, UK). The potentiostat can manages $\mathrm{CV}$ measurements using a MSP430G2553 microcontroller from Texas Instruments, (USA). The system generates a triangular stepped signal with a fixed frequency between two electrodes (CE and RE) and measures the current resulting on the third electrode (WE). The circuit block diagram is shown in Figure 2. The circuitry is based on a $3.7 \mathrm{~V}$ power supply that limited the maximum and minimum voltage generation allowing only a $3.3 \mathrm{~V}$ peak to peak voltage (Vpp); therefore, in order to supply a triangular voltage stimulus a virtual ground at $\mathrm{Vpp} / 2(1.65 \mathrm{~V})$ is set. The electrochemical cell can be then stimulated from a maximum 
voltage of $+1.65 \mathrm{~V}$ and a minimum voltage of $-1.65 \mathrm{~V}$. A 12-bit Digital to analog Converter (DAC) is used to supply the voltage stimulus to the electrochemical cell. This DAC allows an approximately accuracy of approximately $0.8 \mathrm{mV}$ per step. During the positive slope of the voltage signal generation, oxidation processes can be stimulated and monitored, while during the negative slope of the voltage signal the redox reactions can take place and can be monitored in the same way as the oxidation processes. Current is measured by using an transimpedance amplifier constituted by a precision resistance and a voltage amplifier, and then the signal is transformed to voltage. A first order low pass passive filter was implemented to improve the signal to noise ratio, prior to the acquisition of the signal through the 10-bit Analog to Digital Converter (ADC) of the microcontroller. Simultaneously, the reference voltage from the RE is measured through a voltage follower circuit prior to the acquisition using another port of the 10-bit ADC (Figure 2).

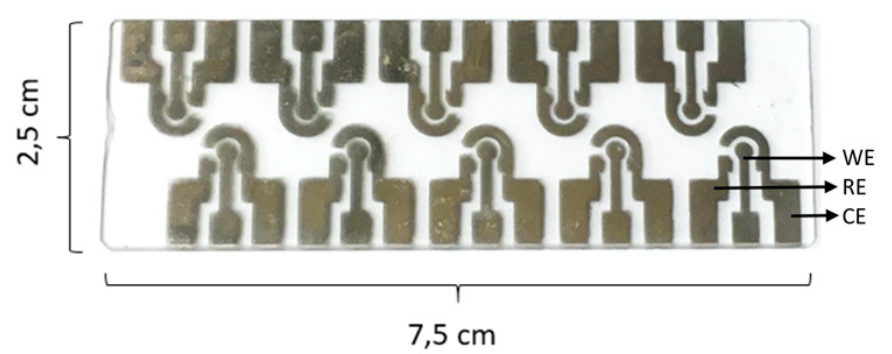

Figure I Electrochemical cells used. I0 set of Au electrodes are arranged in one single glass slide. Each set was composed by three electrodes reference electrode, working electrode and counter electrode (RE,WE and CE).

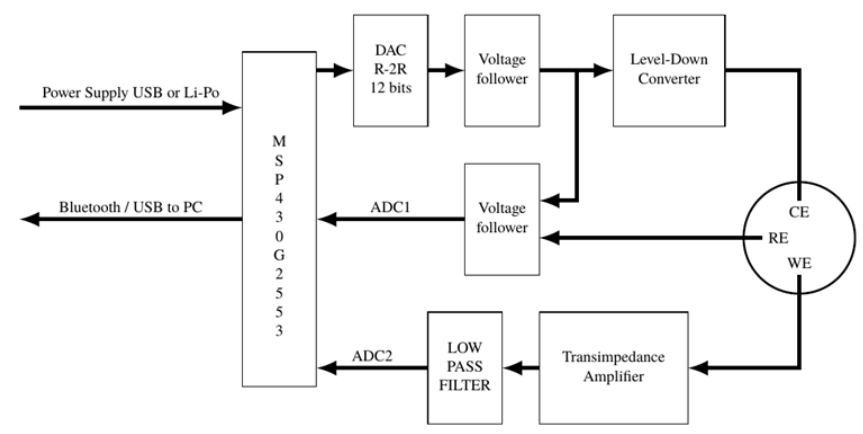

Figure 2 Circuit architecture.

\section{Software}

The microcontroller can generate stepped triangular signals, with a step size of approximately $0.8 \mathrm{mV}$, has a sampling frequency of $125 \mathrm{~Hz}$ and sample the voltage and current signals from the electrochemical cell (Figure 3). The operation frequency of the triangular voltage generation can be set from $1 \mathrm{mHz}$ up to $50 \mathrm{~Hz}$ and are controlled by the internal timer interrupts of the microcontroller to ensure maximum precision. The PC software (Figure 4) designed and programmed for the use of this circuitry allows the configuration of all the parameters needed for the CV and the communicates through Bluetooth or USB with the electronic circuitry.

\section{Results and discussion}

Tests were carried out by duplicate by comparing the measurements of electrochemical cells based on gold electrodes, being exposed to the prepared test solution. Those were measured with $\mathrm{CV}$ to obtain the redox reaction, using both an AUTOLAB potentiostat software, and the circuitry detailed in this work with its software.
Measurement and scan parameters tested in both systems were as follows, a triangular voltage signal with a lower value of $-700 \mathrm{mV}$, upper value of $700 \mathrm{mV}$, a scan rate of $0.1 \mathrm{~V} / \mathrm{s}$ and steps of $10 \mathrm{mV}$. Figure 5 shows the measurements between obtained using the commercial system where the oxidation peak was reported around $0.08 \mathrm{~V}$ and the reduction peak was near $-0.1 \mathrm{~V}$. Using the custom build potentiostat, the electrochemical cell with gold electrodes were tested with the prepared solution and the same setup were used on the AUTOLAB system, the measurements of the Figure 6 were obtained from the software developed and our circuit. On the graphs, the redox process is observed, and the peak of oxidation and reduction are close to the values of $0.08 \mathrm{~V}$ and $-0.10 \mathrm{~V}$ respectively, very similar to those reported by the commercial equipment, the difference in the current measured on the redox peaks between our system and the commercial is due to electronic components tolerance and the low pass filter, which can be adjusted through software amplification options, or by setting a different gain in the transimpedance amplifier of the circuitry.
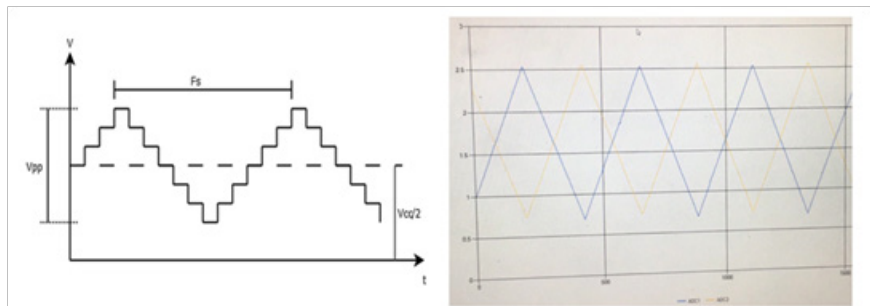

Figure 3 Cyclic Voltammetry signal example (Left) theoretical model; (Right) as displayed in the custom software and measured by the custom circuitry.

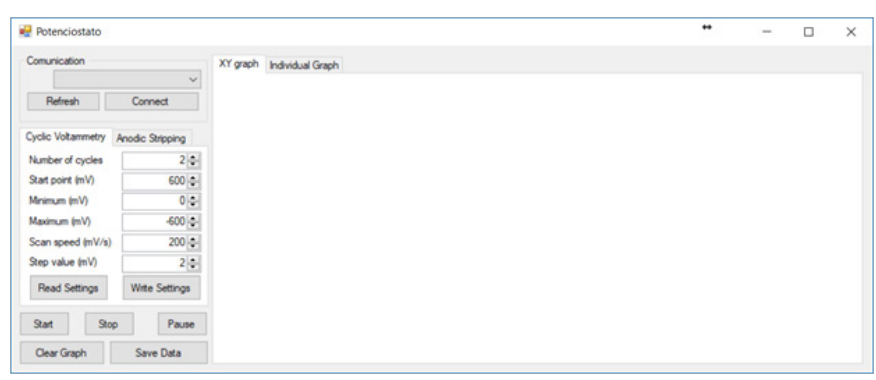

Figure 4 PC software interface.

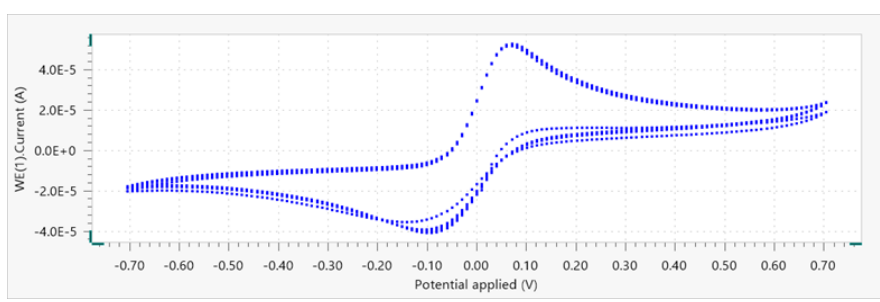

Figure $5 \mathrm{CV}$ measurements using the Au electrodes and test solution measured with AUTOLAB system.

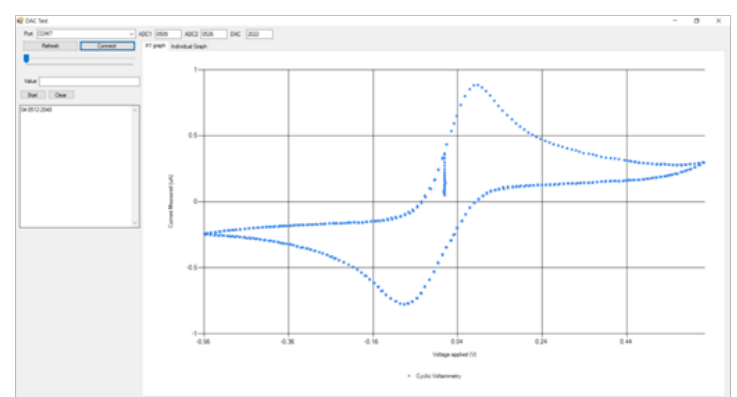

Figure $6 \mathrm{CV}$ measurements using the Au electrodes and test solution measured with the developed system. 


\section{Conclusion}

The development of a portable, low power and custom made potentiostat for our specific requirements allows the reduction of size and weight of portable circuitry. In this case, we achieved a $5,34 \mathrm{~cm}$ $\mathrm{x} 4,45 \mathrm{~cm}$ and $20 \mathrm{~g} \mathrm{CV}$ system that can be embedded in biosensing applications (Figure 7) with potentials in the range of $\pm 1.65 \mathrm{~V}$, that can measure from microamperes to a maximum of $10 \mathrm{~mA}$. Data can be sent or received via USB or remotely via Bluetooth using a low power voltage supply (USB or LiPo battery) allowing its use in portable applications such as remote biosensors even in the cases where wired communication is not allowed or limited. The reduction in the cost allows the incorporation of the circuity in single applications without the need of further laboratory equipment. Also, the use of USB or Li-Po battery to power up the circuity, the same used by cell phones, allows its use in field applications making possible the use of biosensors even when a power supply is not available. The high availavility of used components allows the use of many circuits in parallel in order to get more results in the same amount of time, and with a interconnection system over Bluetooth, WiFi or ZigBee protocols allowing the implementation of electrochemical sensor wireless networks. Also, more capabilities can be easily incorporated by using the same hardware and adding some extra software codification. Some of these extra capabilities can be anodic stripping and linear sweep. In addition, reduce the area and weigh of the circuitry, the use of surface mounted device (SMD) components for the OpAmps and Microcontroller is suggested. For the software the addition of a database to store common procedures and previous measurement seasons can improve the user experience and data handling in the sampling process.

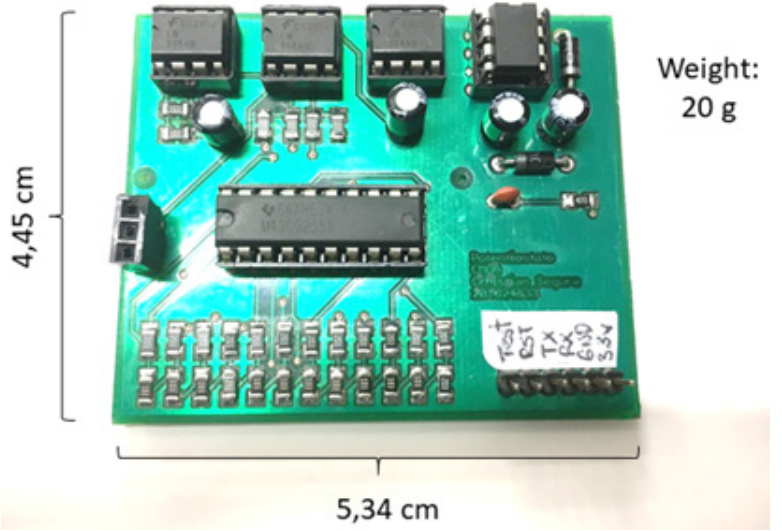

Figure 7 Photo of the developed system.

\section{Acknowledgements}

The authors acknowledge the support of the Universidad de los Andes, and 727 Colciencias doctoral scholarships for their support during the development of this system.

\section{Conflict of interest}

The author declares no conflict of interest.

\section{References}

1. Nordin NA, Jamil AJ, Mat Som ASC, et al. Potentiostat readout circuit design for a 3-electrode electrochemical biosensing measurement system. Control Syst Grad Res Colloquium, ICSGRC 2016 - Proceeding, Malaysia: IEEE; 2017. p. 159-163.
2. Koutilellis GD, Economou A, Efstathiou CE. A potentiostat featuring an integrator transimpedance amplifier for the measurement of very low currents - Proof-of-principle application in microfluidic separations and voltammetry. Rev Sci Instrum. 2016;87(3):034101.

3. Liu WC, Hou JW, Syu YS, et al. A time-based potentiostat for wide dynamic range current measurement. IEEE Reg 10 Annu Int Conf Proceedings/TENCON; 2016.

4. Ettenauer J, Zuser K, Kellner K, et al. Development of an automated biosensor for rapid detection and quantification of $E$. coli in water. Procedia Eng. 2015;120:376-379.

5. Huang CY, O Hare D, Chao IJ, et al. Integrated potentiostat for electrochemical sensing of urinary 3-hydroxyanthranilic acid with molecularly imprinted poly (ethylene-co-vinyl alcohol). Biosens Bioelectron. 2015;67:208-213.

6. Narimo H, Fukuda H, Murase H. Estimation of bacterial count by electrochemical method with small potentiostat. 2013;46(4):261-265.

7. Kaur PK, Lee S, Kim B. An Integrated Potentiostat. IDEC Journal of Integrated Circuits and Systems. 2017;3(3):6.

8. Hu Y, Sharma S, Weatherwax J, et al. A portable multi-channel potentiostat for real-time amperometric measurement of multi-electrode sensor arrays. Proc IEEE Int Symp Circuits Syst; 2016. p. 1306-1309.

9. Cruz AF, Norena N, Kaushik A, et al. A low-cost miniaturized potentiostat for point-of-care diagnosis. Biosens Bioelectron. 2014;62:249-254.

10. Giordano GF, Marcia BR Vicentini, Angelo L Gobbi, et al. Pointof-use electroanalytical platform based on homemade potentiostat and smartphone for multivariate data processing. Electrochim Acta. 2016;219:170-177.

11. Dobbelaere T, Philippe M Vereecken, et al. A USB-controlled potentiostat/galvanostat for thin-film battery characterization. HardwareX. 2017;2:34-49.

12. Ramfos I, Vassiliadis N, Blionas S, et al. A compact hybrid-multiplexed potentiostat for real-time electrochemical biosensing applications. Biosens Bioelectron. 2013;47:482-489.

13. Kellner K, Posnicek T, Ettenauer J, et al. A new, low-cost potentiostat for environmental measurements with an easy-to-use PC interface. Procedia Eng. 2015;120:956-960.

14. Meloni GN. Building a microcontroller based potentiostat: A inexpensive and versatile platform for teaching electrochemistry and instrumentation. J Chem Educ. 2016;93(7):1320-1322.

15. Zhang $\mathrm{W}, \mathrm{Xu} \mathrm{Y}, \mathrm{Zou} \mathrm{X}$, et al. A real-time-range potentiostat coupled to nano-Au-modified microband electrode array for high-speed stripping determination of human blood lead. Biosens Bioelectron. 2017;97:267272 .

16. Luo T, Wang H, Song H, et al. CMOS potentiostat for chemical sensing applications. Proc IEEE Sensors, USA: Springer; 2013. 3 p.

17. Arevalo-Ramirez T, Torres CC, Rosero AC, et al. Low cost potentiostat Criteria and considerations for its design and construction. Proc. 2016 IEEE ANDESCON, ANDESCON; 2017

18. Meneses D, Gunasekara DB, Pichetsurnthorn P, et al. Evaluation of in-channel amperometric detection using a dual-channel microchip electrophoresis device and a two-electrode potentiostat for reverse polarity separations. Electrophoresis. 2015;36(3):441-448.

19. Aremo B, Oyebamiji Adeoye M, Obioh IB, et al. A Simplified microcontroller based potentiostat for low-resource applications. Open J Met vol. 2015;5(4):37-46.

20. Steinberg MD, Kassal P, Kereković I, et al. A wireless potentiostat for mobile chemical sensing and biosensing. Talanta. 2015;143:178-183. 